\title{
Hyperuricemia and coronary heart disease mortality: a meta-analysis of prospective cohort studies
}

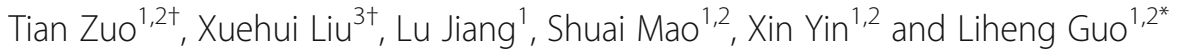

\begin{abstract}
Background: Hyperuricemia may be associated with an increased risk of coronary heart disease (CHD) mortality; however, the results from prospective studies are conflicting. The objective of this study was to assess the association between hyperuricemia and risk of CHD mortality by performing a meta-analysis.

Methods: Pubmed and Embase were searched for relevant prospective cohort studies published until July 2015. Studies were included only if they reported data on CHD mortality related to hyperuricemia in a general population. The pooled adjusted relative risk (RR) was calculated using a random-effects model.

Results: A total of 14 studies involving 341389 adults were identified. Hyperuricemia was associated with an increased risk of CHD mortality (RR: 1.14; 95 \% Cl: 1.06-1.23) and all-cause mortality (RR: 1.20; 95 \% Cl: 1.13-1.28). For each increase of $1 \mathrm{mg} / \mathrm{dl}$ of serum uric acid (SUA), the overall risks of CHD and all-cause mortality increased by 20 and $9 \%$, respectively. According to the gender subgroup analyses, hyperuricemia increased the risk of CHD mortality in women (RR: 1.47; 95 \% Cl: 1.21-1.73) compared to men (RR: 1.10; 95 \% Cl: 1.00-1.19). The risk of all-cause mortality was greater in women.
\end{abstract}

Conclusions: Hyperuricemia may modestly increase the risk of $\mathrm{CHD}$ and all-cause mortality. Future research is needed to determine whether urate-lowering therapy has beneficial effects for reducing CHD mortality.

Keywords: Hyperuricemia, Coronary heart disease, Mortality, Meta-analysis

\section{Background}

Coronary heart disease (CHD) is a severe threat to human health and has a high mortality rate. Many traditional risk factors for CHD have been identified, such as hyperlipidemia, hypertension, diabetes, and smoking. Serum uric acid (SUA), the end product of purine metabolism via an enzymatic reaction involving xanthine oxidase, has also been correlated with CHD by several studies [1-3]. However, because of controversial epidemiologic findings and the lack of consistent evidence,

\footnotetext{
* Correspondence: guolh5946@163.com

${ }^{\dagger}$ Equal contributors

${ }^{1}$ The Second Clinical College of Guangzhou University of Chinese Medicine, Guangdong Provincial Hospital of Chinese Medicine, Guangzhou 510120, People's Republic of China

${ }^{2}$ Department of Critical Care Medicine, Guangdong Provincial Hospital of Chinese Medicine, Guangzhou 510120, People's Republic of China

Full list of author information is available at the end of the article
}

whether SUA is an independent and causal risk factor for CHD remains unknown [4-10].

Several observational studies $[4,8,11,12]$ demonstrated that elevated SUA has a predictive value for CHD risk and that hyperuricemia may be an important causal factor for CHD mortality. However, other studies [5, 6, 13-15] contradict this. Many factors may contribute to the conflicting conclusions. Subjectively, differences of the studied populations, sample size, length of follow-up, and methods of statistical analyses could influence the outcome. Objectively, known risk factors, such as age, gender, fat, weight index and other potential confounding factors, under- or over -estimate the association between hyperuricemia and the risk of related disease.

However, regardless of whether hyperuricemia is a causal risk factor for CHD mortality, several pathophysiological mechanisms have been postulated for their relationship. SUA was considered to be a major antioxidant in 
humans with possible beneficial anti-atherosclerotic effects in the early years. However, for patients with hyperuricemia, elevated SUA may have a more negative role by stimulating oxidative stress and causing endothelial dysfunction and inflammatory reactions [16]. Moreover, the formation of oxygen free radicals and platelet adhesiveness are also induced by hyperuricemia [17]. These observations may explain some direct or indirect associations between hyperuricemia and CHD.

A previous meta-analysis [18] suggested that hyperuricemia is associated with the risk of CHD mortality and that the association was stronger in women than men. This study has practical implications regarding the predication and prevention of CHD mortality and has been cited frequently. However, we found that several of the extracted data (RR or $95 \% \mathrm{CI})$ calculated in the metaanalysis differed from the original studies. These errors may alter the overall pooled results. In addition, several relevant prospective studies have been published since the previous meta-analysis was conducted. To accurately and comprehensively estimate the influence of hyperuricemia on CHD mortality in general populations, we performed an updated meta-analysis.

\section{Methods}

\section{Literature search}

We performed a comprehensive literature search in Pubmed and Embase for relevant prospective cohort studies assessing the association between hyperuricemia and CHD mortality. The search covered from the date of inception until July 2015, and there was no language restriction. The searched terms included hyperuricemia, uric acid, coronary disease, coronary heart disease, coronary artery disease, cardiac heart disease, cardiovascular disease, death and mortality. In addition, the reference lists of the selected articles were manually screened for potential studies. Our meta-analysis was conducted according to the checklist of Meta-analysis of Observational Studies in Epidemiology (MOOSE) [19].

\section{Study selection}

Studies that satisfied the following criteria were included: 1) a prospective cohort study of adult subjects; 2) described the association between hyperuricemia and CHD mortality; 3) an inception cohort involving adults without CHD; and 4) reported adjusted risk estimates for CHD mortality, such as relative risk (RR) or hazard ratio (HR) with a $95 \%$ confidence interval $(95 \% \mathrm{CI})$.

\section{Data extraction and quality assessment}

Two authors independently extracted data from all of the included studies using a standardized Excel file. The following data were extracted from each study: first author, publication year, geographical location, sample size, gender, age, duration of follow-up, definition of hyperuricemia, outcome definition, adjusted risk estimates regarding CHD and all-cause mortality, and confounding variables. The primary outcome was the risk estimate for the association between hyperuricemia and CHD mortality. The quality of selected studies was evaluated using the Newcastle-Ottawa Scale [20]. The quality score of the cohort studies was calculated based on three components as follows: selection of the study groups ( $0-4$ points), comparability of study groups $(0-2$ points), and ascertainment of the interest outcome (0-3 points). The score ranges from 0 to 9 points, with a higher score indicating better methodological quality. Disagreements were resolved by consensus.

\section{Statistical analysis}

To standardize the unit of SUA of the included studies, we converted it from $\mu \mathrm{mol} / \mathrm{L}$ to $\mathrm{mg} / \mathrm{dl}$ by dividing by 59.48. If a study reported the association between hyperuricemia and CHD mortality according to an age- or SUA level-specific category, each was included in the meta-analysis. A pooled estimate of the adjusted RR was calculated using the DerSimonian and Laird randomeffects model. Heterogeneity across studies was evaluated using the $\mathrm{I}^{2}$ statistic, which is a quantitative measure of inconsistency across studies. A stratified analysis by gender was conducted to assess the gender-related heterogeneity in the adjusted RR of CHD and all-cause mortality. If evident heterogeneity was present, a sensitivity analysis was conducted by omitting each study in turn to identify a potential source. To explore the impact of the study characteristics, such as gender, study region (Asia vs. nonAsia), duration of follow-up ( $\leq 10$ years vs. $>10$ years), and sample size $(<10,000$ vs. $>10,000)$, on the pooled $R R$, we would conduct a multivariate meta-regression analysis. But only the number of studies providing a same effect size was more than ten can the analysis be done according to the requirements of statistics recommended by the Cochrane Collaboration. Publication bias was assessed using both Begg's test and Egger's test. A two-tailed $p$-value $<0.05$ was considered statistically significant. All statistical analyses were performed using Stata 12.0.

\section{Results \\ Characteristics of the eligible studies}

We retrieved 1373 articles with the initial literature search. Two-hundred-eighty-six articles were excluded because of duplicates. After screening the title or abstract, 1028 studies were excluded, and the remaining 59 were further identified by reading the full-text. According to the predefined inclusion criteria, 14 studies [21-34] enrolling 341389 participants were included in the meta-analysis. Based on the reference lists of the included studies, we retrieved six potential studies, but 
none met our inclusion criteria. Figure 1 shows the detailed search strategy.

The characteristics of the included studies and their participants are summarized in Table 1. Of the 14 included studies, four were performed in the United States [21, 22, 29, 34], five in Europe [24, 26, 30, 31, 33] and five in Asia [22, 25, 27, 28, 32]. All except one [24] were written in English. The sample size of the studies ranged from 1198 [26] to 90393 [32] participants. The duration of follow-up was between 5.4 [23] and 24.9 [27] years. Of these studies, seven [22, 24, 26, 27, 32-34] included both genders, five [23, 25, 28-30] included only men, and two $[21,31]$ included only women. The definition of hyperuricemia ranged from 5.6 to $7.0 \mathrm{mg} / \mathrm{dl}$ in men and from 5.4 to $7.0 \mathrm{mg} / \mathrm{dl}$ in women. Two studies reported the results of RR between hyperuricemia and CHD mortality based on the SUA level [23] and age [21] subgroup. Ten studies [23-25, 27-31, 33, 34] reported the association between the SUA level and CHD mortality based on different categories. Three [21, 22, 26] presented the association the SUA level and CHD mortality based on an increase of $1 \mathrm{mg} / \mathrm{dl}$ in each level, and only one [32] represented it both ways. Nine studies $[21,23-28,32,33]$ reported the association between hyperuricemia and all-cause mortality. The majority of studies defined CHD mortality using the International Classification of Disease (ICD) codes from the hospital records or death certificates. All of the selected studies

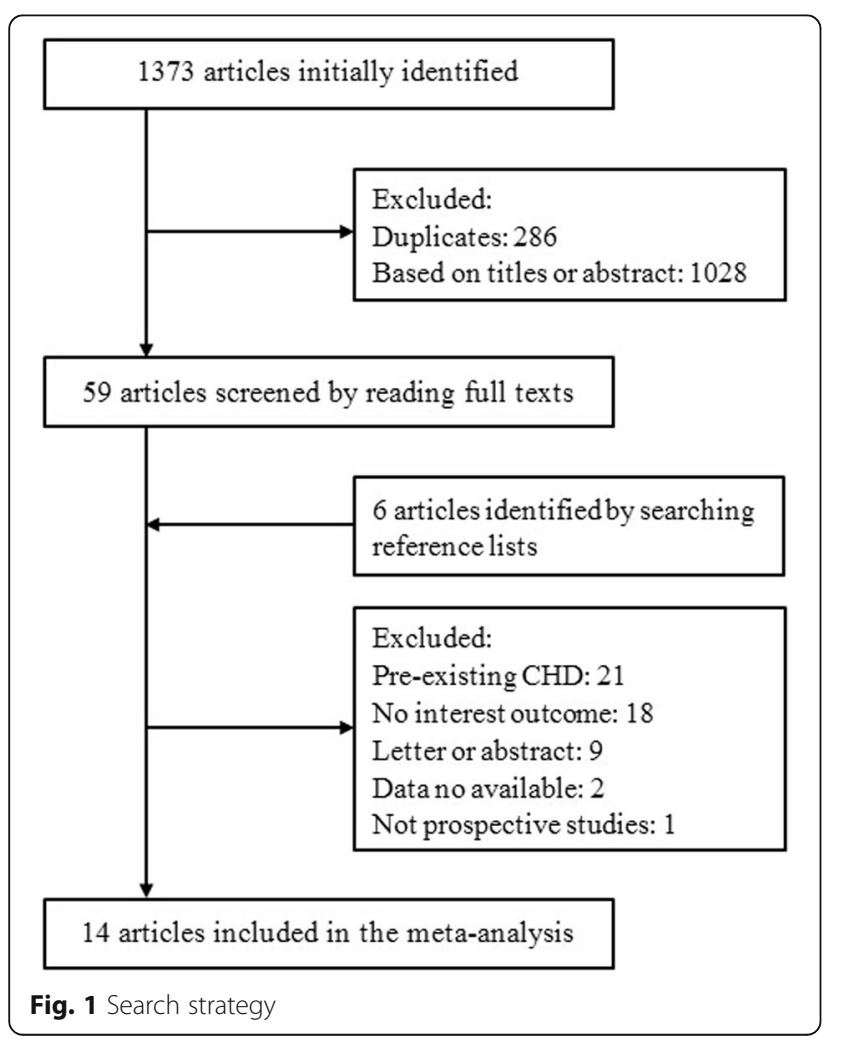

were assessed as high quality according to the NOS scale. The median NOS score of the studies selected was 9 (range from 7 to 9 ).

\section{CHD mortality}

The pooled multivariate adjusted RR for CHD mortality based on 11 studies [23-25, 27-34] was 1.14 (95 \% CI: 1.06-1.23; Fig. 2). A slight heterogeneity between studies was noted $\left(\mathrm{I}^{2}=9.6 \%, p>0.05\right)$. No significant publication bias was present according to Begg's and Egger's test (both $P$ values $>0.05$ ). The pooled adjusted RR for CHD mortality was 1.10 (95 \% CI: 1.00-1.19) among men [23-25, 27-30, 32] and 1.47 (95 \% CI: 1.21-1.73) among women $[24,27,31,32]$. There was no evident heterogeneity between studies with respect to outcomes $\left(\mathrm{I}^{2}=0.0 \%, 3.9 \%\right)$.

For each increase of $1 \mathrm{mg} / \mathrm{dl}$ in the SUA level, the pooled adjusted RR for CHD mortality based on four studies [21, 22, 26, 32] was 1.20 (95 \% CI: 1.10-1.29; Fig. 3). Significant heterogeneity between studies was observed $\left(\mathrm{I}^{2}=53.3 \%, p<0.05\right)$. Subsequently, a sensitivity analysis was performed to identify the potential source of heterogeneity. Exclusion of one study [32] conducted by Chen et al. did not change the pooled results (RR: 1.31 ; $95 \%$ CI: $1.15-1.31$ ), but no evidence of heterogeneity was observed among the remaining studies $\left(\mathrm{I}^{2}=0.0 \%, p=0.53\right)$. Further exclusion of any single study did not significantly alter the overall combined RR (data not shown). The pooled adjusted RR for each increase of $1 \mathrm{mg} / \mathrm{dl}$ in SUA was 1.18 (95 \% CI: $1.08-1.28$ ) among men [22, 26] and 1.31 (95 \% CI: 1.18-1.43) among women [21, 22, 26]. No significant heterogeneity between studies was noted with respect to outcomes $\left(\mathrm{I}^{2}=0.0 \%\right.$ for both genders).

\section{All-cause mortality}

Nine studies [21, 23-28, 32, 33] reported outcomes on all-cause mortality. The pooled adjusted RR for all-cause mortality based on seven studies [23-25, 27, 28, 32, 33] was 1.20 (95 \% CI: 1.13-1.28; Fig. 4). Significant heterogeneity between studies was observed $\left(\mathrm{I}^{2}=63.5 \%\right.$, $p<0.01)$. There was a significant publication bias according to Begg's test $(p<0.05)$ and Egger's test $(p<0.01)$. Because the number of studies was less than ten, a multivariate meta-regression was not performed. We only performed a sensitivity analysis by excluding each study individually to identify the potential source of heterogeneity. Exclusion of any single study did not significantly alter the heterogeneity among the remaining studies. The pooled adjusted RR for all-cause mortality was 1.15 (95\% CI: 1.08-1.23) among men and 1.38 (95 \% CI: 1.22-1.54) among women. There was slight heterogeneity between studies with respect to outcomes $\left(\mathrm{I}^{2}=30.6 \%, 32.5 \%\right)$. 
Table 1 Characteristics of studies included in the meta-analysis

\begin{tabular}{|c|c|c|c|c|c|c|c|c|}
\hline Study & Year & Age (years) & $\begin{array}{l}\text { Participants } \\
\text { (\%men) }\end{array}$ & $\begin{array}{l}\text { Duration } \\
\text { (years) }\end{array}$ & $\begin{array}{l}\text { Hyperuricemia } \\
\text { definition }(\mathrm{mg} / \mathrm{dl})\end{array}$ & Confounding factors & Outcome definition & NOS score \\
\hline CHA-W [21] & 1989 & $35-64$ & 6797 white women in USA & 11.5 & $\begin{array}{l}\text { Per } 1 \mathrm{mg} / \mathrm{dl} \\
\text { increase }\end{array}$ & $\begin{array}{l}\text { Age, weight, smoking, DBP, cholesterol, } \\
\text { antihypertensive drugs, ECG abnormalities }\end{array}$ & ICD-8 codes on death certificates & $4 / 2 / 3$ \\
\hline NHANES-I [22] & 2000 & $25-74(48.1)$ & $\begin{array}{l}5962(45.6) \text { non-institutionalized } \\
\text { population in USA }\end{array}$ & 16.4 & $\begin{array}{l}\text { M: 7.0; W: 5.6; Per } \\
1 \mathrm{mg} / \mathrm{dl} \text { increase }\end{array}$ & $\begin{array}{l}\text { Age, race, BMl, cholesterol, smoking, } \\
\text { alcohol, hypertension, DM, diuretic use }\end{array}$ & $\begin{array}{l}\text { ICD-9 codes on death certificates, } \\
\text { and/or a proxy interview }\end{array}$ & $4 / 2 / 3$ \\
\hline Tomita [23] & 2000 & $25-60$ & $\begin{array}{l}49,413 \text { male railroad workers } \\
\text { in Japan }\end{array}$ & 5.4 & M: 6.5 & Age & $\begin{array}{l}\text { ICD-9 codes on health and } \\
\text { pension records }\end{array}$ & $3 / 1 / 3$ \\
\hline $\begin{array}{l}\text { Belgian } \\
\text { study [24] }\end{array}$ & 2001 & $25-74$ & 9710 (53.9) subjects in Belgia & 10 & M: 7.0; W: 5.4 & $\begin{array}{l}\text { M:age, DBP, educational level, smoking, } \\
\text { alcohol; W:age, cholesterol, SBP, BMI, } \\
\text { smoking, alcohol, DM }\end{array}$ & ICD-9 codes on hospital records & $4 / 2 / 3$ \\
\hline KMIC [25] & 2004 & $44.6 \pm 8.7$ & 22,698 men in Korea & 9 & M: 7.0 & Age, DM, hypertension, cholesterol, smoking & Death certificates & $4 / 2 / 3$ \\
\hline Baibas [26] & 2005 & $\geq 25$ & 1198 (42) adults in rural Greece & 14 & $\begin{array}{l}\text { Per } 1 \mathrm{mg} / \mathrm{dl} \\
\text { increase }\end{array}$ & $\begin{array}{l}\text { Age, village, educational level, weight, } \\
\text { smoking, alcohol, SBP, blood glucose, } \\
\text { cholesterol, triglycerides }\end{array}$ & ICD-9 codes on death certificates & $4 / 2 / 3$ \\
\hline $\begin{array}{l}\text { Atomic bomb } \\
\text { Study [27] }\end{array}$ & 2005 & $20-89(48.6)$ & $\begin{array}{l}10,615 \text { ( } 36.4) \text { Japanese atomic } \\
\text { bomb survivors }\end{array}$ & 24.9 & $M: 7.0 ; W: 6.0$ & $\begin{array}{l}\text { Age, BMI, smoking, alcohol, SBP, DM, } \\
\text { cholesterol, histories of hypertension, } \\
\text { kidney disease; malignant tumor; } \\
\text { estimated radiation dose }\end{array}$ & $\begin{array}{l}\text { ICD-7 to } 10 \text { codes on } \\
\text { death certificates }\end{array}$ & $3 / 2 / 3$ \\
\hline $\begin{array}{l}\text { Israeli male } \\
\text { Study [28] }\end{array}$ & 2006 & $49 \pm 7$ & 9125 men in Israel & 23 & M: 5.6 & $\begin{array}{l}\text { age, BMI, SBP, DM, smoking, LVH on ECG, } \\
\text { cholesterol }\end{array}$ & $\begin{array}{l}\text { ICD-9 codes on death certificates } \\
\text { and hospital records }\end{array}$ & $4 / 2 / 3$ \\
\hline MRFIT [29] & 2008 & $41-63$ & 9105 men in USA & 17 & M: 7.0 & $\begin{array}{l}\text { Clinical center, age, BP, cholesterol, } \\
\text { triglyceride, smoking, family history of AMI, } \\
\text { aspirin and diuretic use, BMI }\end{array}$ & $\begin{array}{l}\text { ICD-9 and } 10 \text { codes on } \\
\text { death certificates }\end{array}$ & $4 / 2 / 3$ \\
\hline VHMPP-M [30] & 2008 & 41.6 & 83,863 Austrian men & 13.6 & M: 6.7 & $\begin{array}{l}\text { Age, BMI, BP, cholesterol, triglycerides, } \\
\text { glucose, smoking, year of examination }\end{array}$ & $\begin{array}{l}\text { ICD-9 and } 10 \text { codes on death } \\
\text { certificates; autopsy records }\end{array}$ & $4 / 2 / 3$ \\
\hline VHMPP-W [31] & 2008 & $62.3 \pm 8.8$ & 28,613 elderly Austrian women & 15.2 & $W: 5.4$ & $\begin{array}{l}\text { Age, BMI, BP, cholesterol, triglycerides, } \\
\text { glucose, smoking, occupational status, } \\
\text { year of examination }\end{array}$ & $\begin{array}{l}\text { ICD-9 and } 10 \text { codes on death } \\
\text { certificates; autopsy records }\end{array}$ & $4 / 2 / 3$ \\
\hline $\begin{array}{l}\text { Chinese cohort } \\
\text { study [32] }\end{array}$ & 2009 & $51.5 \pm 11.5$ & 90,393 (46.3) adults in Taiwan & 8.2 & $\begin{array}{l}M \text { and } W: 7.0 ; \text { Per } \\
1 \mathrm{mg} / \mathrm{dl} \text { increase }\end{array}$ & $\begin{array}{l}\text { Age, BMl, cholesterol, triglycerides, DM, } \\
\text { hypertension, smoking, alcohol, sex }\end{array}$ & ICD-9 codes on death certificates & $4 / 2 / 3$ \\
\hline Puddu [33] & 2014 & $35-74$ & $\begin{array}{l}2888 \text { (44.1) adults from } \\
\text { Gubbio in Italy }\end{array}$ & 13.5 & $M$ and $W: 7.0$ & $\begin{array}{l}\text { Age, gender, SBP, cholesterol, smoking, BMI, } \\
\text { blood glucose, e-GFR }\end{array}$ & ICD-9 codes on death certificates & $4 / 2 / 3$ \\
\hline $\begin{array}{l}\text { NHANES-III } \\
{[34]}\end{array}$ & 2015 & 45.3 & 11,009 (45.9) adults in USA & 14.5 & $M$ and $W: 6.3$ & $\begin{array}{l}\text { Age, sex, race, BMI, SBP, smoking, HDL, } \\
\text { cholesterol, antihypertensive drug }\end{array}$ & $\begin{array}{l}\text { ICD-10 codes on death } \\
\text { certificates }\end{array}$ & $4 / 2 / 3$ \\
\hline
\end{tabular}

AMI acute myocardial infraction, BMI body mass index, BP blood pressure, CHA Chicago Heart Association, DM diabetes mellitus, DBP diastolic blood pressure, ECG electrocardiograph, e-GFR estimated-glomerular filtration rate, $H D L$ high-density lipoprotein, ICD international classification of disease, KMIC Korea Medical Insurance Corporation, $L V H$ left ventricular hypertrophy, $M$ men, MRFIT Multiple Risk factor Intervention Trial, NHANES National Health and Nutrition Examination Survey, SBP systolic blood pressure, VHMPP Vorarlberg Health Monitoring and Promotion Program, W women 


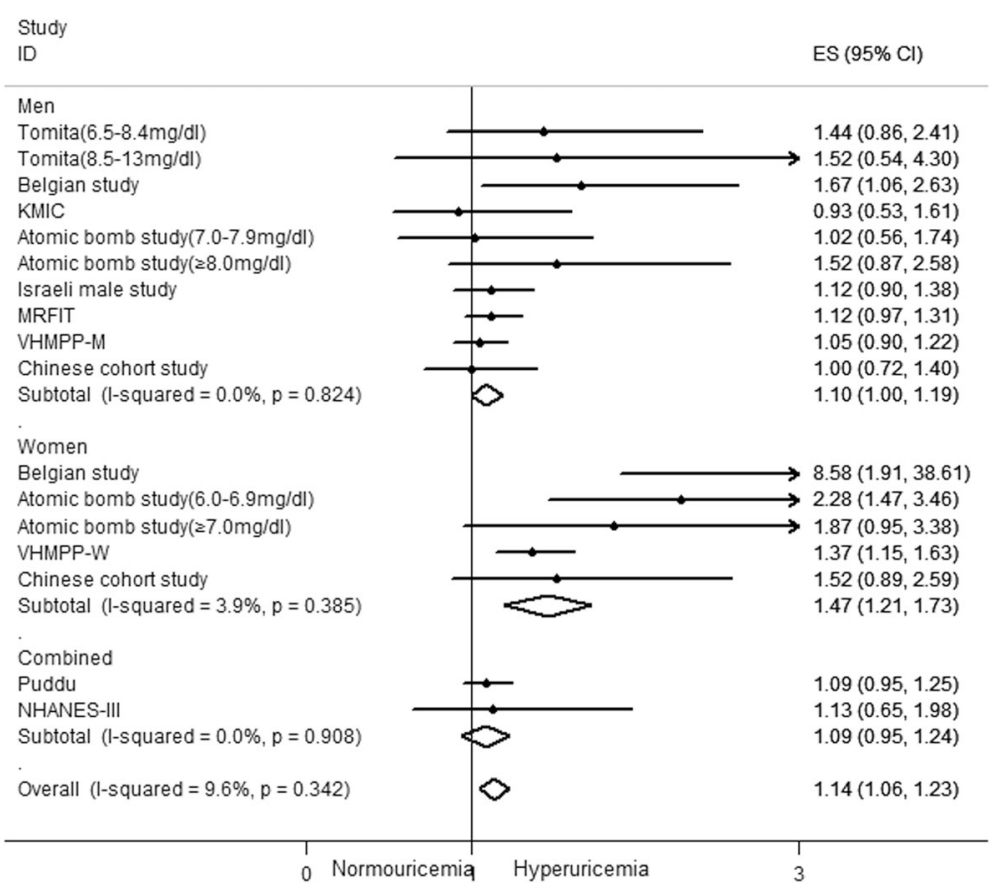

Fig. 2 Forest plot of association between hyperuricemia and coronary heart disease mortality

Based on this, the heterogeneity among the seven studies may be related to gender.

For each increase of $1 \mathrm{mg} / \mathrm{dl}$ in the SUA level, the pooled adjusted RR for all-cause mortality based on three studies [21, 26, 32] was 1.09 (95 \% CI: 1.02-1.17, Fig. 5). Significant heterogeneity between studies was observed $\left(\mathrm{I}^{2}=59.4 \%, p<0.05\right)$.

\section{Meta-regression}

A multivariate meta-regression was performed to identify the predefined potential source of heterogeneity regarding CHD mortality. It demonstrated that the heterogeneity across studies was related to gender $(p<0.05)$, rather than region, follow-up duration and sample size.

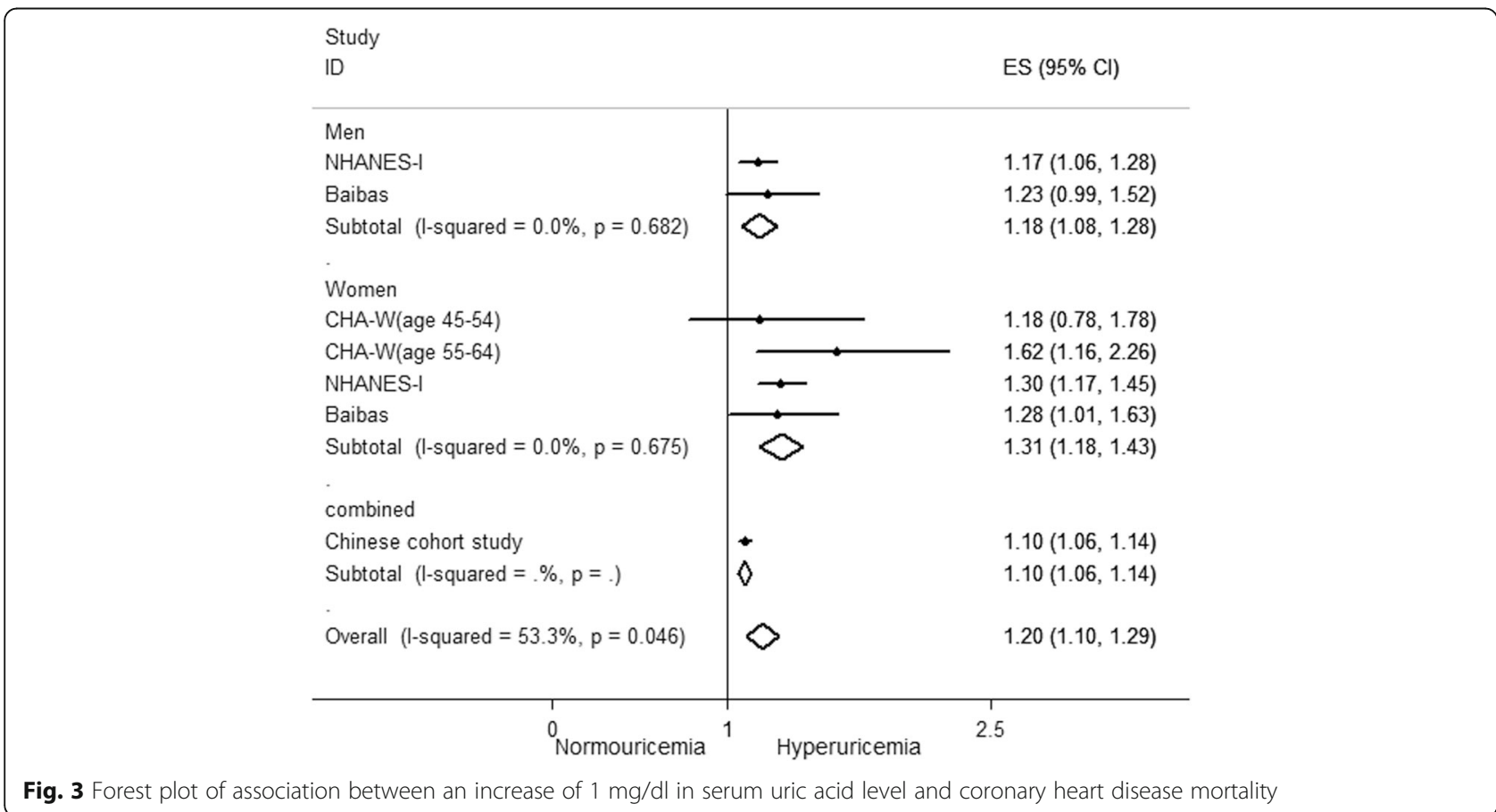




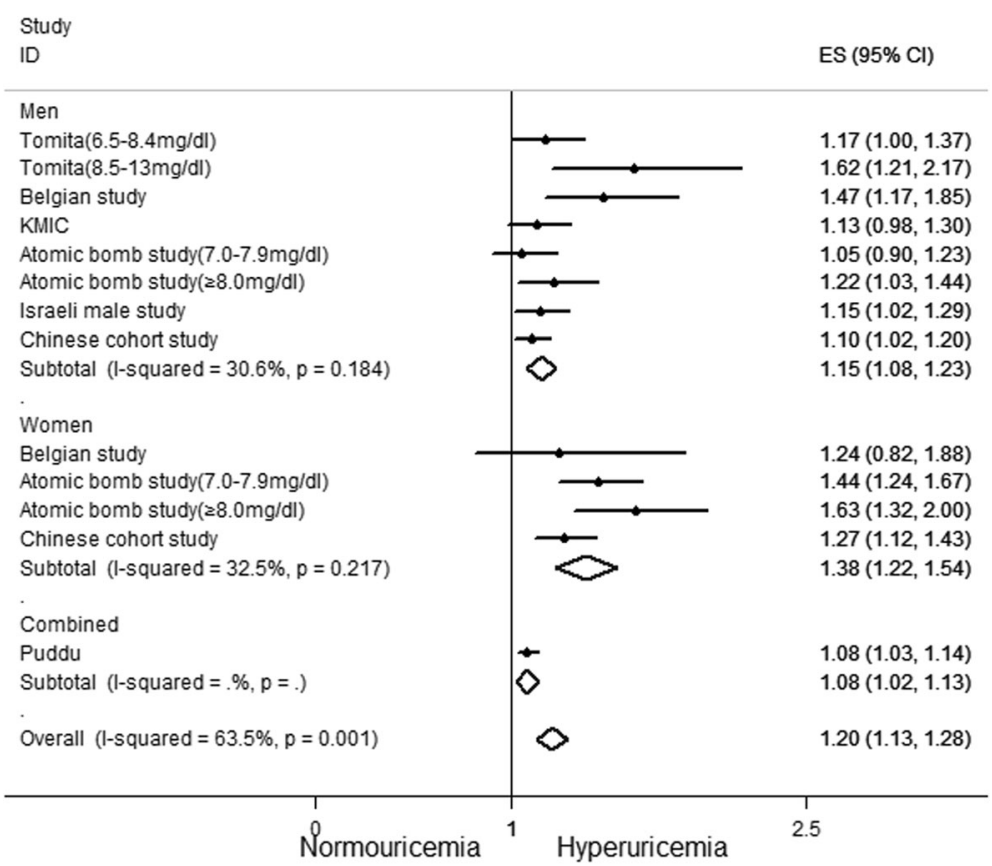

Fig. 4 Forest plot of association between hyperuricemia and all-cause mortality

\section{Discussion}

Our updated meta-analysis demonstrates that hyperuricemia is associated with a modest but statistically significant increased risk of CHD and all-cause mortality. For each increase of $1 \mathrm{mg} / \mathrm{dl}$ of SUA, the overall risks of CHD and all-cause mortality increased by 20 and $9 \%$, respectively. According to gender subgroup analyses, hyperuricemia increased the risk of CHD mortality in women (RR: 1.47; 95 \% CI: 1.21-1.73) compared to men (RR: 1.10; $95 \%$ CI: 1.00-1.19). The risk of all-cause mortality was greater for women.

Hyperuricemia has been correlated with hypertension, hyperlipidemia, diabetes, metabolic syndrome and renal disease, all of which could contribute to increased CHD and all-cause mortality. Over the past few decades, relevant studies $[4,5,8,13,14,21-37]$ have provided

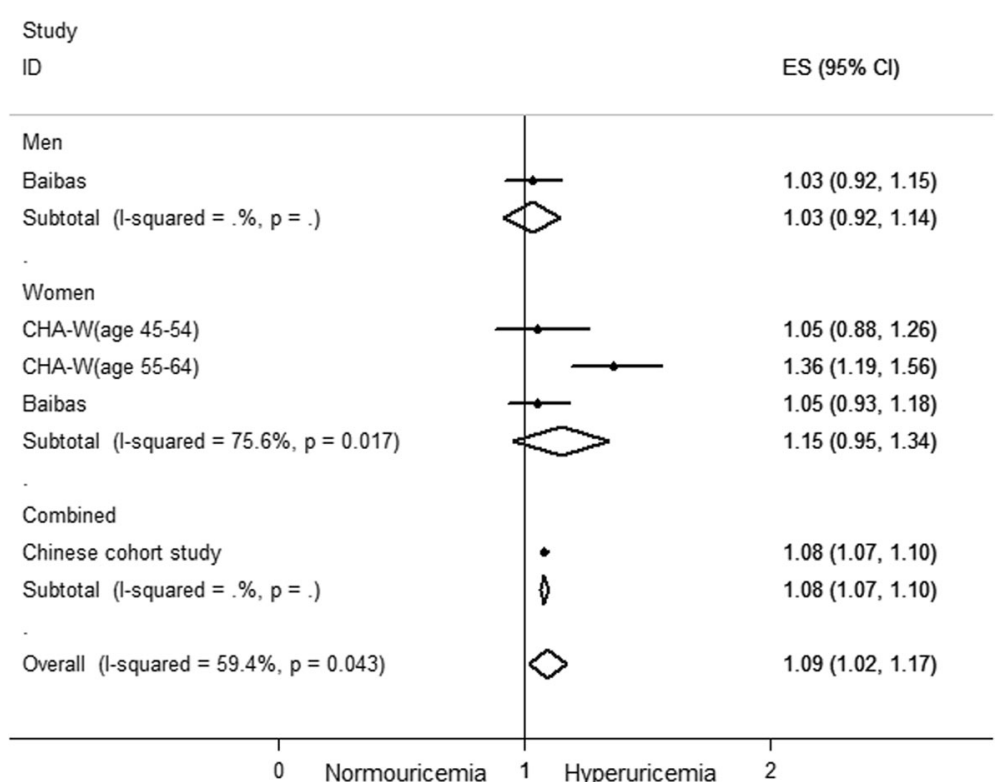

Fig. 5 Forest plot of association between an increase of $1 \mathrm{mg} / \mathrm{dl}$ in serum uric acid level and all-cause mortality 
conflicting evidence regarding the association between hyperuricemia and CHD or all-cause mortality; therefore, whether hyperuricemia is an independent risk and causal factor for CHD mortality remains unclear. This phenomenon may be related to the differences in the enrolled populations, definition of hyperuricemia, outcomes studied, follow-up duration, sample size and statistical adjustment.

To further investigate the association between hyperuricemia and CHD or all-cause mortality, Zhao et al. [38] and Kim et al. [18] assessed it using a meta-analysis. The study conducted by Zhao et al. showed that elevated SUA increased the risk of cardiovascular mortality (RR: 1.37; $95 \%$ CI 1.19-1.57) and all-cause mortality (RR: 1.24; $95 \%$ CI: 1.09-1.42). The risk of cardiovascular mortality was more pronounced in women (RR: 1.35; 95 \% CI: 1.06-1.72). However, the association between hyperuricemia and CHD mortality was not assessed independently. Our meta-analysis suggests that hyperuricemia is associated with all-cause mortality in both genders (Fig. 4), whereas Zhao et al. only observed this association for men (for women: RR 1.05; 95 \% CI 0.791.39). The explanation for such findings may be related to the different inclusion criteria. Different from Zhao et al., we chose an inception cohort involving adults without CHD. In the other study, Kim et al. demonstrated that hyperuricemia was associated with an increased risk of CHD mortality (RR 1.16; 95 \% CI 1.01-1.30), similar to our findings. However, there were several mistakes when the data ( $R R$ or $95 \% \mathrm{CI}$ ) were extracted from the original studies (Additional file 1: Tables S1 and S2) [24, $26,30,31]$, which may have altered the pooled outcomes. After correcting the mistake in their study, the overall pooled outcomes were not significantly changed. For the subgroup analysis, however, an increase of $1 \mathrm{mg} /$ $\mathrm{dl}$ in the SUA level was associated with CHD mortality in both genders (Fig. 3), which is different from the previous meta-analysis [18] (RR 1.10, 95 \% CI 0.96-1.24 among men; RR 1.17, 95 \% CI 0.97-1.38 among women) but similar to ours. Therefore, this difference is because of the data extraction mistakes. Researchers found that patients with angiographically confirmed CHD with SUA levels in the upper quartile were five times more likely to die than those in the lowest quartile [39]. The risk of mortality increased by $26 \%$ for each increase of $1 \mathrm{mg} / \mathrm{dl}$ in the SUA level and reflected the doseresponse relationship between the SUA levels and allcause mortality in patients with CHD. In a subsequent study in 2015, von Lueder et al. [40] investigated the relationship between SUA and clinical outcomes in subjects with acute myocardial infarction complicated by reduced left ventricular function or/and heart failure. Their study showed that SUA strongly and independently predict adverse outcomes, and the finding of dose dependent HR for all-cause and cardiovascular mortality through survival curves according to quartiles of baseline SUA. They concluded that the quantifcation of SUA could improve clinical risk stratifcation of patients with LV systolic dysfunction and/or HF following acute MI. Similarly, our meta-analysis is also in conformity to the results of the above two studies, but we suggests such a dose-response relationship in the general population, which may help to confirm the causal assiciation between HUA and CHD mortality from a different perspective.

Although it remains unclear as to the role that elevated SUA plays in CHD development and mortality, the evidence suggests the following possible mechanisms. First, several studies [41-45] suggested that hyperuricemia has a pathogenic role and predictive value in the development of hypertension. Therefore, a causal link to the development of hypertension is a plausible explanation for the possible increased cardiovascular risk in patients with hyperuricemia [46]. Second, increased SUA levels may encourage lipid peroxidation and promote the oxidation of low-density lipoprotein (LDL) cholesterol [47], which may play a role in the development of atherosclerosis [48] and would also explain its association with CHD [49]. Interestingly, because human atherosclerosis plaques contain more UA than normal artery walls, researchers propose that SUA may have a direct role in the atherosclerosis process [50]. Third, hyperuricemia may induce endothelial dysfunction, which is predicted to promote the early development of atherosclerosis and precede plaque formation [51]. The deposition of urate crystals on the vessel wall could cause an inflammatory reaction to then directly injure the vascular intima and ultimately activating the platelet and blood coagulation system. Finally, hyperuricemia also promotes thrombosis $[52,53]$ and activates monocyte chemotactic protein-1 [46], an important chemokine in atherosclerosis.

Greater attention has been paid to whether uratelowing therapy improves cardiovascular outcomes. Hyperuricemia is frequently encountered in hypertensive patients. Patients with hyperuricemia and hypertension are associated with a 3- to 5-fold increase in CHD compared to patients with normal SUA levels [54]. LIFE is the first study to demonstrate that reducing the SUA levels is associated with a reduction of cardiovascular events in hypertensive patients [55]. Allopurinol, a xanthine inhibitor, is frequently used in hyperuricemic patients to reduce the SUA level. A meta-analysis of 10 studies showed that allopurinol is associated with a small but significant reduction in blood pressure [56]. High-dose allopurinol therapy may prolong the time to chest pain during exercise and improve endothelial dysfunction in patients with stable angina pectoris [57]. These effects of allopurinol may be 
valuable for reducing future cardiovascular mortality. Encouragingly, a prospective cohort study $(n=7135)$ demonstrated that high-dose allopurinol treatment is associated with a lower risk of cardiovascular events and mortality [58]. Although previous studies have not yet provided direct evidence that urate-lowering therapy reduces the risk of CHD mortality in hyperuricemic patients, the studies discussed above provided some positive data. Hence, further research is necessary.

Several limitations of this meta-analysis should be acknowledged. First, although a multivariable adjustment was conducted in most of the included studies, confounding effects from other unadjusted risk factors may exist. Notably, the majority of the considered studies were not adjusted for renal functionality or diuretics or purine and fructose intake, which significantly influence the SUA level. In particular, renal functionality is a main determinant of CHD and its mortality. So more studies with subject-restriction to only those participants with normal eGFR are needed to conduct in the future, only by this, the causal relationship between hyperuricemia and risk of CHD mortality could be accurately detected. Second, our results may be less convincing because the SUA level may also be associated with other organ damage, such as heart failure or IMT, or to the development of other relevant diseases, such as type 2 diabetes [59]. Third, it's important to note that there was a significant publication bias with regards to all-cause mortality. We attempted to minimize publication bias by searching electronic databases with no language restriction; however, because many researchers didn't focus on all-cause mortality and report it as a primary or secondary outcome in related studies, and studies with negative results and that are written in non-English languages are less likely to be published, publication bias still exists. Despite these limitations, our study has several strengths. This meta-analysis is based on large prospective cohort studies with a long follow-up period in many different areas. Most of the studies included in our meta-analysis reported the adjusted RR. We assessed the quality of individual studies using the Newcastle-Ottawa Scale, which shows that all of the studies were of high quality, making our results more reliable. In addition, compared to the previous meta-analysis [18], we included the latest studies and corrected the data errors extracted from the four papers (Additional file 1: Tables S1 and S2) $[24,26,30,31]$ that we included. Because of this, our statistical subgroup analyses suggested that regardless of hyperuricemia or an increase of $1 \mathrm{mg} / \mathrm{dl}$ in the SUA level, both are associated with CHD mortality in both genders. Furthermore, we conducted a multivariate meta-regression analysis on the log-transformed scale of RR to explore the impact of the study characteristics.

\section{Conclusions}

In conclusion, our meta-analysis suggests that hyperuricemia may modestly increase the risk of $\mathrm{CHD}$ and allcause mortality. Because there are safe and effective methods to reduce SUA levels, future studies should focus on the role of urate-lowering therapy for reducing CHD mortality.

\section{Additional file}

Additional file 1: Table S1. The erroneous and correct data for the association between hyperuricemia and CHD mortality. Table S2. The erroneous and correct data for the association between an increase of $1 \mathrm{mg} / \mathrm{dl}$ in serum uric acid level and CHD mortality. (DOC $24 \mathrm{~kb}$ )

\section{Abbreviations \\ CHD: Coronary heart disease; HR: Hazard ratio; ICD: International Classification of Disease; LDL: Low-density lipoprotein; MOOSE: Meta-analysis of Observational Studies in Epidemiology; RR: Relative risk; SUA: Serum uric acid}

\section{Acknowledgments}

There was no funding source for this research.

\section{Availability of data and materials}

Data and Materials presented in the main paper or additional supporting files.

\section{Authors' contributions}

The design of the study was done by LHG. XHL carried out the literature research, performed the data extraction and statistical analysis. TZ assisted with critical analyses and re-analyses of results and writing the manuscript. $\mathrm{LJ}$ assisted in the data extraction and examination. $\mathrm{XHL}, \mathrm{SM}$ and $\mathrm{XY}$ contributed to the preparation and critical review of the manuscript. TZ and $\mathrm{XHL}$ contributed equally to this work. All authors read and approved the final manuscript.

\section{Competing interests}

The authors declare that they have no competing interests.

Consent for publication

Not applicable.

Ethics approval and consent to participate

Not applicable, our manuscript does not contain any individual person's data.

\section{Author details}

${ }^{1}$ The Second Clinical College of Guangzhou University of Chinese Medicine, Guangdong Provincial Hospital of Chinese Medicine, Guangzhou 510120, People's Republic of China. 'Department of Critical Care Medicine, Guangdong Provincial Hospital of Chinese Medicine, Guangzhou 510120, People's Republic of China. ${ }^{3}$ Department of Cardiology, Yichang Hospital of Chinese Medicine, Clinical Medical College of Chinese Medicine, China Three Gorges University, Yichang 443000, People's Republic of China.

Received: 19 April 2016 Accepted: 22 October 2016

Published online: 28 October 2016

\section{References}

1. Gertler MM, Garn SM, Levine SA. Serum uric acid in relation to age and physique in health and in coronary heart disease. Ann Intern Med. 1951;34(6):1421-31.

2. Klein R, Klein BE, Cornoni JC, Maready J, Cassel JC, Tyroler HA. Serum uric acid. Its relationship to coronary heart disease risk factors and cardiovascular disease, Evans County, Georgia. Arch Intern Med. 1973;132(3):401-10. 
3. Brand FN, McGee DL, Kannel WB, Stokes 3rd J, Castelli WP. Hyperuricemia as a risk factor of coronary heart disease: The Framingham Study. Am J Epidemiol. 1985;121(1):11-8.

4. Freedman DS, Williamson DF, Gunter EW, Byers T. Relation of serum uric acid to mortality and ischemic heart disease. The NHANES I Epidemiologic Follow-up Study. Am J Epidemiol. 1995;141(7):637-44.

5. Wannamethee SG, Shaper AG, Whincup PH. Serum urate and the risk of major coronary heart disease events. Heart. 1997;78(2):147-53.

6. Culleton BF, Larson MG, Kannel WB, Levy D. Serum uric acid and risk for cardiovascular disease and death: The Framingham heart study. Ann Intern Med. 1999;131(1):7-13.

7. Dobson A. Is raised serum uric acid a cause of cardiovascular disease or death? Lancet. 1999;354(9190):1578.

8. Liese AD, Hense HW, Lowel H, Doring A, Tietze M, Keil U. Association of serum uric acid with all-cause and cardiovascular disease mortality and incident myocardial infarction in the MONICA Augsburg cohort. Epidemiology. 1999;10(4):391-7.

9. Yusuf S, Bosch J. Urate levels as a predictor of cardiac deaths: causal relation or mere association? Eur Heart J. 2002;23(10):760-1.

10. Feig DI, Kang DH, Johnson RJ. Uric acid and cardiovascular risk. N Engl J Med. 2008;359(17):1811-21.

11. Weir CJ, Muir SW, Walters MR, Lees KR. Serum urate as an independent predictor of poor outcome and future vascular events after acute stroke. Stroke. 2003;34(8):1951-6.

12. Bos MJ, Koudstaal PJ, Hofman A, Witteman JCM, Breteler MMB. Uric acid is a risk factor for myocardial infarction and stroke-The Rotterdam Study. Stroke. 2006;37(6):1503-7.

13. Hu P, Seeman TE, Harris TB, Reuben DB. Is serum uric acid level associated with all-cause mortality in high-functioning older persons: MacArthur studies of successful aging? J Am Geriatr Soc. 2001;49(12):1679-84.

14. Sakata K, Hashimoto T, Ueshima H, Okayama A. Absence of an association between serum uric acid and mortality from cardiovascular disease: NIPPON DATA 80, 1980-1994. National Integrated Projects for Prospective Observation of Non-communicable Diseases and its Trend in the Aged. Eur J Epidemiol. 2001;17(5):461-8

15. Wheeler JG, Juzwishin KD, Eiriksdottir G, Gudnason V, Danesh J. Serum uric acid and coronary heart disease in 9,458 incident cases and 155,084 controls: prospective study and meta-analysis. PLoS Med. 2005:2(3):e76.

16. Puddu P, Puddu GM, Cravero E, Vizioli L, Muscari A. The relationships among hyperuricemia, endothelial dysfunction, and cardiovascular diseases: Molecular mechanisms and clinical implications. J Cardiol. 2012;59(3):235-42.

17. Johnson RJ, Kang DH, Feig D, Kivlighn S, Kanellis J, Watanabe S, Tuttle KR, Rodriguez-Iturbe B, Herrera-Acosta J, Mazzali M. Is there a pathogenetic role for uric acid in hypertension and cardiovascular and renal disease? Hypertension. 2003;41(6):1183-90

18. Kim YS, Guevara JP, Kim KM, Choi HK, Heitjan DF, Albert DA. Hyperuricemia and coronary heart disease: A systematic review and meta-analysis. Arthritis Care Res. 2010;62(2):170-80.

19. Stroup DF, Berlin JA, Morton SC, Olkin I, Williamson GD, Rennie D, Moher D, Becker BJ, Sipe TA, Thacker SB. Meta-analysis of observational studies in epidemiology: a proposal for reporting. Meta-analysis of Observational Studies in Epidemiology (MOOSE) group. JAMA. 2000; 283(15):2008-12.

20. Stang A. Critical evaluation of the Newcastle-Ottawa scale for the assessment of the quality of nonrandomized studies in meta-analyses. Eur J Epidemiol. 2010;25(9):603-5.

21. Levine W, Dyer AR, Shekelle RB, Schoenberger JA, Stamler J. Serum uric acid and 11.5-year mortality of middle-aged women: Findings of the Chicago Heart Association Detection Project in Industry. J Clin Epidemiol. 1989;42(3): 257-67.

22. Fang J, Alderman MH. Serum uric acid and cardiovascular mortality: The NHANES I Epidemiologic Follow-up Study, 1971-1992. J Am Med Assoc. 2000;283(18):2404-10.

23. Tomita M, Mizuno S, Yamanaka H, Hosoda Y, Sakuma K, Matuoka Y, Odaka M, Yamaguchi M, Yosida H, Morisawa H, et al. Does hyperuricemia affect mortality? A prospective cohort study of Japanese male workers. J Epidemiol. 2000;10(6):403-9.

24. Aboa Eboule AC, De Smet P, Dramaix M, De Backer G, Kornitzer M. Relation between uricemia and all-causes cardiovascular and coronary mortality in both genders of non-selected sample of the Belgium population. Rev Epidemiol Sante Publique. 2001;49(6):531-9.
25. Jee SH, Lee SY, Kim MT. Serum uric acid and risk of death from cancer, cardiovascular disease or all causes in men. Eur J Cardiovasc Prev Rehabil. 2004;11(3):185-91.

26. Baibas N, Trichopoulou A, Voridis E, Trichopoulos D. Residence in mountainous compared with lowland areas in relation to total and coronary mortality. A study in rural Greece. J Epidemiol Community Health. 2005;59(4):274-8.

27. Hakoda M, Masunari N, Yamada M, Fujiwara S, Suzuki G, Kodama K, Kasagi F. Serum uric acid concentration as a risk factor for cardiovascular mortality: A longterm cohort study of atomic bomb survivors. J Rheumatol. 2005:32(5):906-12.

28. Gerber Y, Tanne D, Medalie JH, Goldbourt U. Serum uric acid and long-term mortality from stroke, coronary heart disease and all causes. Eur J Cardiovasc Prev Rehabil. 2006;13(2):193-8.

29. Krishnan E, Svendsen K, Neaton JD, Grandits G, Kuller LH. Long-term cardiovascular mortality among middle-aged men with gout. Arch Intern Med. 2008;168(10):1104-10.

30. Strasak A, Ruttmann E, Brant L, Kelleher C, Klenk J, Concin H, Diem G, Pfeiffer K, Ulmer H. Serum uric acid and risk of cardiovascular mortality: a prospective long-term study of 83,683 Austrian men. Clin Chem. 2008;54(2): 273-84.

31. Strasak AM, Kelleher CC, Brant LJ, Rapp K, Ruttmann E, Concin H, Diem G, Pfeiffer KP, Ulmer $\mathrm{H}$. Serum uric acid is an independent predictor for all major forms of cardiovascular death in 28,613 elderly women: A prospective 21-year follow-up study. Int J Cardiol. 2008;125(2):232-9.

32. Chen JH, Chuang SY, Chen HJ, Wen-Ting YEH, Wen-Harn PAN. Serum uric acid level as an independent risk factor for all-cause, cardiovascular, and ischemic stroke mortality: A chinese cohort study. Arthritis Care Res. 2009;61(2):225-32.

33. Puddu PE, Bilancio G, Terradura Vagnarelli O, Lombardi C, Mancini M, Zanchetti A, Menotti A. Serum uric acid and eGFR-CKDEPI differently predict long-term cardiovascular events and all causes of deaths in a residential cohort. Int J Cardiol. 2014;171(3):361-7.

34. Zalawadiya SK, Veeranna V, Mallikethi-Reddy S, Bavishi C, Lunagaria A, Kottam A, Afonso L. Uric acid and cardiovascular disease risk reclassification: Findings from NHANES III. Eur J Prev Cardiol. 2015;22(4):513-8.

35. Niskanen LK, Laaksonen DE, Nyyssonen K, Alfthan G, Lakka HM, Lakka TA, Salonen JT. Uric acid level as a risk factor for cardiovascular and all-cause mortality in middle-aged men: A prospective cohort study. Arch Intern Med. 2004;164(14):1546-51.

36. Meisinger C, Koenig W, Baumert J, Doring A. Uric acid levels are associated with all-cause and cardiovascular disease mortality independent of systemic inflammation in men from the general population: the MONICA/KORA cohort study. Arterioscler Thromb Vasc Biol. 2008;28(6):1186-92.

37. Wang $Y, X u Y$, Hu D, Guo X, Zhao D, Li J. Joint association of ankle-brachial index and serum uric acid on the outcomes of six-year all-cause mortality and cardiovascular mortality in Chinese patients. Int J Cardiol. 2012;158(1): $144-5$.

38. Zhao G, Huang L, Song M, Song Y. Baseline serum uric acid level as a predictor of cardiovascular disease related mortality and all-cause mortality: A meta-analysis of prospective studies. Atherosclerosis. 2013;231(1):61-8.

39. Bickel C, Rupprecht HJ, Blankenberg S, Rippin G, Hafner G, Daunhauer A Hofmann KP, Meyer J. Serum uric acid as an independent predictor of mortality in patients with angiographically proven coronary artery disease. Am J Cardiol. 2002;89(1):12-7.

40. von Lueder TG, Girerd N, Atar D, Agewall S, Lamiral Z, Kanbay M, Pitt B, Dickstein K, Zannad F, Rossignol P. Serum uric acid is associated with mortality and heart failure hospitalizations in patients with complicated myocardial infarction: findings from the High-Risk Myocardial Infarction Database Initiative. Eur J Heart Fail. 2015;17(11):1144-51.

41. Sanchez-Lozada LG, Tapia E, Avila-Casado C, Soto V, Franco M, Santamaria J, Nakagawa T, Rodriguez-Iturbe B, Johnson RJ, Herrera-Acosta J. Mild hyperuricemia induces glomerular hypertension in normal rats. Am J Physio Renal Physiol. 2002;283(5):F1105-10

42. Mazzali M, Kanellis J, Han L, Feng L, Xia YY, Chen Q, Kang DH, Gordon KL, Watanabe $S$, Nakagawa $T$, et al. Hyperuricemia induces a primary renal arteriolopathy in rats by a blood pressure-independent mechanism. Am J Physiol Renal Physiol. 2002;282(6):F991-7.

43. Mazzali M, Hughes J, Kim YG, Jefferson JA, Kang DH, Gordon KL, Lan $H Y$, Kivlighn S, Johnson RJ. Elevated uric acid increases blood pressure in the rat by a novel crystal-independent mechanism. Hypertension. 2001;38(5):1101-6. 
44. Dyer AR, Liu K, Walsh M, Kiefe C, Jacobs Jr DR, Bild DE. Ten-year incidence of elevated blood pressure and its predictors: the CARDIA study. Coronary Artery Risk Development in (Young) Adults. J Hum Hypertens. 1999;13(1):13-21.

45. Jossa F, Farinaro E, Panico S, Krogh V, Celentano E, Galasso R, Mancini M, Trevisan M. Serum uric acid and hypertension: the Olivetti heart study. J Hum Hypertens. 1994;8(9):677-81.

46. Baker JF, Krishnan E, Chen L, Schumacher HR. Serum uric acid and cardiovascular disease: Recent developments, and where do they leave us? Am J Med. 2005;118(8):816-26.

47. De Scheerder IK, van de Kraay AM, Lamers JM, Koster JF, de Jong JW, Serruys PW. Myocardial malondialdehyde and uric acid release after shortlasting coronary occlusions during coronary angioplasty: potential mechanisms for free radical generation. Am J Cardiol. 1991;68(4):392-5.

48. Iribarren C, Folsom AR, Eckfeldt JH, McGovern PG, Nieto FJ. Correlates of uric acid and its association with asymptomatic carotid atherosclerosis: the ARIC Study. Atherosclerosis Risk in Communities. Ann Epidemiol. 1996;6(4):331-40.

49. Gomez M, Vila J, Elosua R, Molina L, Bruguera J, Sala J, Masia R, Covas MI, Marrugat J, Fito M. Relationship of lipid oxidation with subclinical atherosclerosis and 10-year coronary events in general population. Atherosclerosis. 2014;232(1):134-40.

50. Suarna C, Dean RT, May J, Stocker R. Human atherosclerotic plaque contains both oxidized lipids and relatively large amounts of alpha-tocopherol and ascorbate. Arterioscler Thromb Vasc Biol. 1995;15(10):1616-24.

51. Higgins P, Dawson J, Lees KR, McArthur K, Quinn TJ, Walters MR. Xanthine oxidase inhibition for the treatment of cardiovascular disease: a systematic review and meta-analysis. Cardiovasc Ther. 2012;30(4):217-26.

52. Kuwano K, Ikeda H, Oda T, Nakayama H, Koga Y, Toshima H, Imaizumi T. Xanthine oxidase mediates cyclic flow variations in a canine model of coronary arterial thrombosis. Am J Physiol. 1996;270(6 Pt 2):H1993-9.

53. Visy JM, Le Coz P, Chadefaux B, Fressinaud C, Woimant F, Marquet J, Zittoun J, Visy J, Vallat JM, Haguenau M. Homocystinuria due to 5,10methylenetetrahydrofolate reductase deficiency revealed by stroke in adult siblings. Neurology. 1991;41(8):1313-5.

54. Alderman M, Aiyer KJ. Uric acid: role in cardiovascular disease and effects of losartan. Curr Med Res Opin. 2004;20(3):369-79.

55. Dahlof B, Devereux RB, Kjeldsen SE, Julius S, Beevers G, de Faire U, Fyhrquist F, Ibsen H, Kristiansson K, Lederballe-Pedersen O, et al. Cardiovascular morbidity and mortality in the Losartan Intervention For Endpoint reduction in hypertension study (LIFE): a randomised trial against atenolol. Lancet. 2002;359(9311):995-1003.

56. Agarwal V, Hans N, Messerli FH. Effect of allopurinol on blood pressure: a systematic review and meta-analysis. J Clin Hypertens (Greenwich). 2013; 15(6):435-42.

57. Rajendra NS, Ireland S, George J, Belch JJ, Lang CC, Struthers AD. Mechanistic insights into the therapeutic use of high-dose allopurinol in angina pectoris. J Am Coll Cardiol. 2011;58(8):820-8.

58. Wei L, Mackenzie IS, Chen Y, Struthers AD, MacDonald TM. Impact of allopurinol use on urate concentration and cardiovascular outcome. Br J Clin Pharmacol. 2011;71(4):600-7.

59. Cicero AF, Derosa G, Rosticci M, D'Addato S, Agnoletti D, Borghi C, Brisighella Heart Study group. Long-term predictors of impaired fasting glucose and type 2 diabetes in subjects with family history of type 2 diabetes: a 12-years follow-up of the Brisighella Heart Study historical cohort. Diabetes Res Clin Pract. 2014;104(1):183-8.

\section{Submit your next manuscript to BioMed Central and we will help you at every step:}

- We accept pre-submission inquiries

- Our selector tool helps you to find the most relevant journal

- We provide round the clock customer support

- Convenient online submission

- Thorough peer review

- Inclusion in PubMed and all major indexing services

- Maximum visibility for your research

Submit your manuscript at www.biomedcentral.com/submit

C Biomed Central 